\title{
Structural Evolution of Near-Surface Layers in NiTi Alloy Caused by an Ion Implantation
}

\author{
Z. Swiatek ${ }^{a, *}$, M. Michalec $^{b}$, N. Levintant-Zayonts ${ }^{c}$, J. Bonarski $^{a}$, A. Budziak $^{d}$, \\ O. BONCHYK ${ }^{e}$ AND G. SAVITSKIJ ${ }^{e}$ \\ ${ }^{a}$ Institute of Metallurgy and Materials Science, PAS, Reymonta 25, 30-059 Kraków, Poland \\ ${ }^{b}$ Jagiellonian University, Ingardena 3, 30-069 Kraków, Poland \\ ${ }^{c}$ Institute of Fundamental Technological Research, PAS, Pawińskiego 5B, 02-106 Warsaw, Poland \\ ${ }^{d}$ Niewodniczański Institute of Nuclear Physics, PAS, E. Radzikowskiego 152, 31-342 Kraków, Poland \\ ${ }^{e}$ Institute for Applied Problems of Mechanics and Mathematics NASU, Naukova 5, 79601 Lviv, Ukraine \\ The results of X-ray diffraction studies on structural changes in the near-surface layers in the NiTi alloy \\ caused by nitrogen-ion implantation with the energy $E=50 \mathrm{keV}$ and the fluence $D=10^{18} \mathrm{~cm}^{-2}$ are presented. \\ X-ray diffractometry, using the Philips diffractometer type X'Pert in the Bragg-Brentano geometry, was used to \\ identify the phase composition of NiTi alloy. For layer by layer analysis of structural changes in the near-surface \\ layers, the D8 Discover Bruker diffractometer with polycapilar beam optics was used. The ion-implanted NiTi \\ alloy in the near-surface layer exhibits five phases: the dominating austenite phase, two martensitic phases and \\ a small amount of the $\mathrm{Ni}_{4} \mathrm{Ti}_{3}$ and NTi phases. Along with the decreasing thickness of the near-surface layer \\ investigated in material an increasing fraction of the $\mathrm{Ni}_{4} \mathrm{Ti}_{3}$ and NTi phases was observed. With the thickness of \\ this layer about $340 \mathrm{~nm}$, besides still existing the austenite, $\mathrm{Ni}_{4} \mathrm{Ti}_{3}$ and NTi phases, only one martensitic phase \\ is present in the alloy. Further decrease of the thickness of the near-surface layer to about $170 \mathrm{~nm}$ leads to the \\ increasing fraction of the $\mathrm{Ni}_{4} \mathrm{Ti}_{3}$ and NTi phases.
}

PACS: 68.55.- a, 68.49.Uv

\section{Introduction}

Shape memory alloys (SMAs) are metals which exhibit two unique properties: pseudo-elasticity and the shape memory effect. SMAs have been exploited for a range of applications, including aerospace, biomedical engineering, cavitation-resistant surfaces, and microelectromechanical systems. Among SMAs, the NiTi alloys are the most popular [1, 2]. Moreover, they exhibit good corrosion resistance and biocompatibility, tolerance to severe environmental conditions, and thus they are the most important engineering materials. Their specific and superior properties are due to reversible thermoelastic martensitic transformation. The interest in shape memory alloys as biomaterials and their use in medical devices have increased recently. In the case of NiTi, the problem of increasing of surface protective properties and, at the same time, simultaneous preservation of functional properties of shape memory materials is a subject of research and development [3].

In general, implantation process may be one way to enhance the mechanical properties of surface, such as resistance to corrosion, wear and fatigue shape memory alloy.

* corresponding author; e-mail:

nmswiate@al.imim-pan.krakow.pl
Conventional ion implantation is a line-of-sight process in which ions are extracted from plasma, accelerated, and bombarded into a device. A systematic study of the effect of oxygen, carbon, zinc, zirconium and argon ions implantation on NiTi surface chemistry and its mechanical and shape memory properties for medical applications has been conducted recently $[4,5]$. The analysis of phase composition revealed that the modified layers were complex composites of implanted ions and the secondary phases of NiTi. Many investigations explored the effect of ion implantation into sequences of phase transformations, characteristic temperatures, structure changes of near-surface layers in the ion-implanted NiTi alloy and resulted in the alteration of the chemical composition of NiTi surfaces to a depth from a few hundred nanometers to $1 \mu \mathrm{m}[6,7]$.

In this article we report the investigations carried out on a commercial NiTi shape memory alloy. In our case, NiTi shape memory alloys has been modified by $\mathrm{N}^{+}$ion implantation. The ion implantation method has precise capabilities for modification of thin surface layers on metals and alloys including their chemical composition, crystal structure, physical and mechanical properties.

\section{Experimental methods}

The equiatomic NiTi (Nitinol) (Shape Memory Corporation, Japan) martensitic form was used in our in- 
vestigations. The samples $\left(22 \times 5.4 \times 0.25 \mathrm{~mm}^{3}\right)$ were annealed at $300{ }^{\circ} \mathrm{C}$ for $30 \mathrm{~min}$ in vacuum and then cooled in the furnace. The surface of NiTi was cleaned using a solution containing $10 \% \mathrm{NClO}_{4}$ and $90 \%$ acetic acid. Nitrogen ion implantation (fluence $10^{18} \mathrm{~cm}^{-2}$, energy $50 \mathrm{keV}$ ) was carried out using a typical semi-industrial implanter IMJON (Surface Layer Division, IFTR PAS, Warsaw). X-ray diffractometry, using the Philips diffractometer, type X'Pert in the Bragg-Brentano geometry, was used to identify the phase composition of NiTi alloy samples in both unimplanted conditions and after implantation with nitrogen. $\mathrm{Cu} K_{\alpha}$ radiation (wavelength $\lambda=0.154184 \mathrm{~nm}$ ) diffracted by the sample was selected by a graphite monochromator. For the layer by layer analysis of structural changes in the near-surface layers, the D8 Discover Bruker diffractometer with polycapilar beam optics was used. The scanning voltage of the X-ray tube was $40 \mathrm{kV}$, the current was $25 \mathrm{~mA}$, the exposure time was $10 \mathrm{~s}$ and the measured angle, $2 \theta$, was from $25^{\circ}$ to $95^{\circ}$. The scanning step was $0.02^{\circ}$. Lattice parameters were determined using the Philips X'Pert Plus software for all detected peaks. For strain determination the so-called $\sin ^{2} \psi$ method [8] was used. In this method the strain is derived from directional measurements of the interplanar spacing $d$ as a function of the angle between the diffraction vector and an arbitrary direction in the specimen.

The profiles of chemical composition of the ion-implanted NiTi alloy were determined by the secondary ion mass spectrography (SIMS) at the Cameca IMS-6F device.

\section{Results and discussion}

Studies began with the determination of chemical and phase compositions of the ion-implanted NiTi alloy. The SIMS analysis was used to determine compositional variation of the elemental components with depth. The depth distributions of the chemical composition in the surface-modified NiTi alloy are given in Fig. 1. As can be seen in this figure, the modified near-surface area contains three sub-layers: an outer layer compositionally

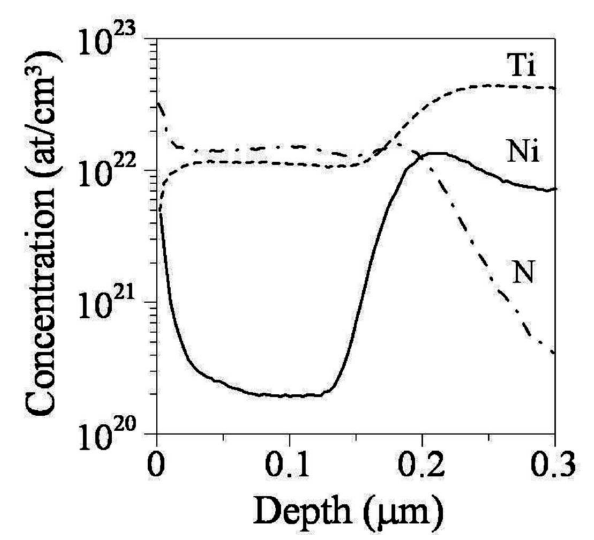

Fig. 1. Experimental SIMS profiles of $\mathrm{Ni}, \mathrm{Ti}$ and $\mathrm{N}$ distribution in the ion-implanted NiTi alloy.

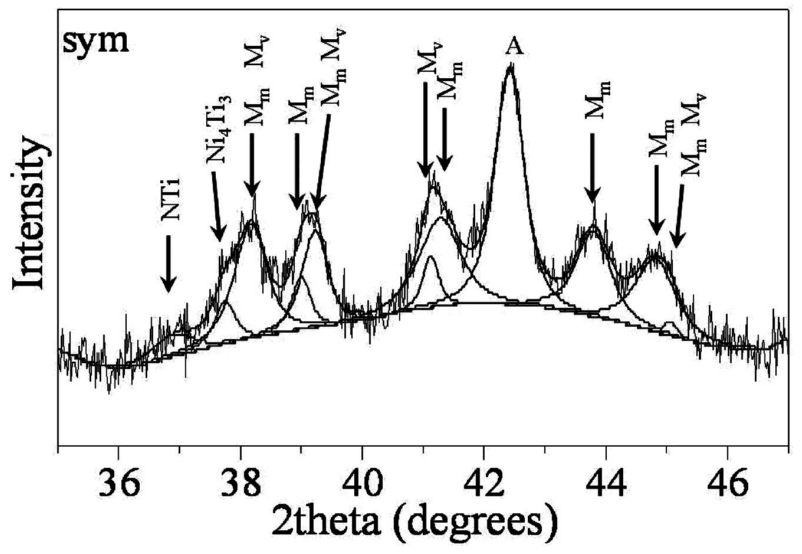

Fig. 2. The X-ray diffraction pattern of the ion-implanted NiTi alloy obtained in the Bragg-Brentano geometry in the symmetrical mode.

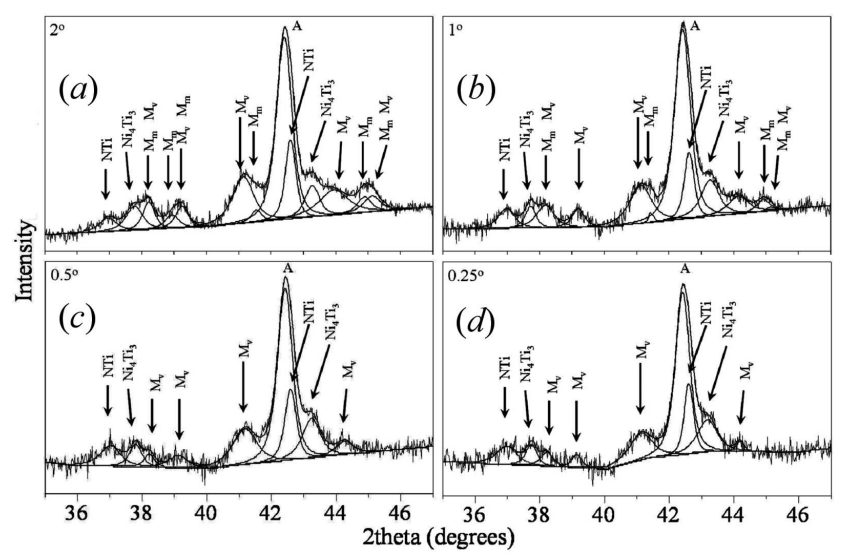

Fig. 3. Grazing incident X-ray diffraction patterns of NiTi samples recorded at different incident angles: $2^{\circ}$ $-\mathrm{PD} \approx 1.3 \mu \mathrm{m}(\mathrm{a}), 1^{\circ}-\mathrm{PD} \approx 670 \mathrm{~nm}(\mathrm{~b}), 0.5^{\circ}-$ $\mathrm{PD} \approx 340 \mathrm{~nm}(\mathrm{c})$ and $0.25^{\circ}-\mathrm{PD} \approx 170 \mathrm{~nm}(\mathrm{~d})$.

graded in nickel, a median layer rich in titanium, and an inner layer compositionally graded in nickel.

The X-ray diffraction pattern of the ion-implanted NiTi alloy is shown in Fig. 2. From the obtained results, it can be seen that the alloy at $20^{\circ} \mathrm{C}$ exhibits the existence of a mixture phase of cubic (A) and monoclinic (dominating $M_{\mathrm{m}}$ and a small amount of $M_{\mathrm{v}}$ ). Apart from the austenite (A) and martensite $\left(M_{\mathrm{m}}\right.$ and $\left.M_{\mathrm{v}}\right)$ NiTi peaks, the pattern of the implanted sample displays peaks of new phases at $2 \theta=36.81^{\circ}$ and $37.7^{\circ}$, respectively. According to [9] the phase composition of the Ni-enriched layer in the sample implanted at $70^{\circ} \mathrm{C}$ can generally be identified as $\mathrm{Ni}_{4} \mathrm{Ti}_{3}$ and increasing the implantation temperature to $180^{\circ} \mathrm{C}$ leads presumably to the formation of $\mathrm{Ni}_{4} \mathrm{Ti}_{3}$ and $\mathrm{Ni}_{3} \mathrm{Ti}$ phases. From the profiles of chemical composition of the ion-implanted NiTi alloy (Fig. 1), it can be assumed that such situation may occur on an outer layer of tens of nanometers thick and at the depth 


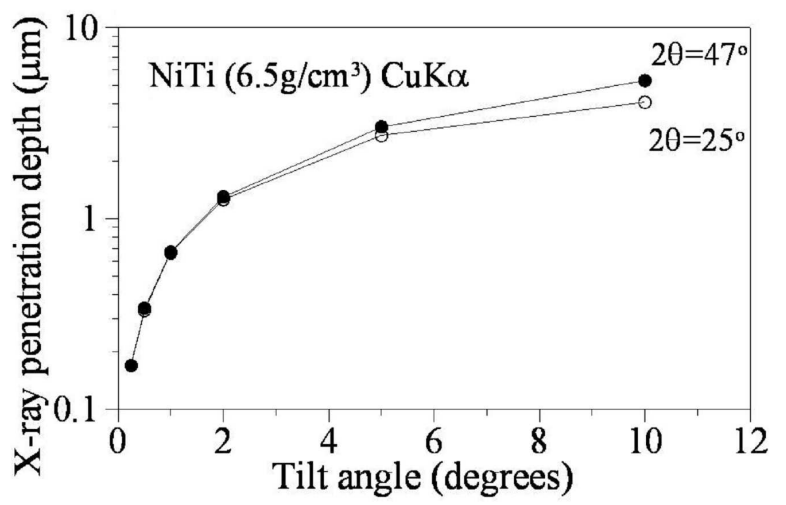

Fig. 4. The penetration depth of X-ray $\mathrm{Cu} K_{\alpha}$ radiation in the NiTi sample $\left(6.5 \mathrm{~g} / \mathrm{cm}^{3}\right)(\mathrm{PD})$ for the measured angle interval, $2 \theta$, vs. the incident angle.

of $150-200 \mathrm{~nm}$ from the sample surface. The formation of NTi phase may take place in the whole near-surface region up to the depth of $200 \mathrm{~nm}$. The observed crystallographic distances, calculated for the given $2 \theta$, are compared with expected values described in JCPDS [10]. The peak at $2 \theta=36.81^{\circ}$ is attributed to NTi with a cubic structure (PDF card number 00-006-0642) since $2 \theta$ for NTi is 36.80 and the peaks at $2 \theta=37.7^{\circ}$ can be attributed to $\mathrm{Ni}_{4} \mathrm{Ti}_{3}$ with a rhombohedral structure (PDF card number 00-039-1113).
To verify the above identifications, the phase composition of the near-surface layers has been determined by GIXRD (grazing incidence X-ray diffraction), using the D8 Discover Bruker diffractometer with polycapilar beam optics. The patterns of implanted NiTi alloy are shown in Fig. 3. The measurements were collected at 4 different specimen positions (incident angles $0.25^{\circ}, 0.5^{\circ}, 1^{\circ}$ and $\left.2^{\circ}\right)$. The penetration depth of X-ray $\mathrm{Cu} K$ radiation in the NiTi sample for the measured angle interval, $2 \theta$, vs. the incident angle is shown in Fig. 4. The value of X-ray penetration depth decreased from $1.3 \mu \mathrm{m}$ for the incident angle $2^{\circ}$ to about $170 \mathrm{~nm}$ for the incident angle $0.25^{\circ}$.

As can be seen from GIXRD patterns of the implanted NiTi sample in Fig. 3, together with the decreased value of X-ray penetration depth, increased reflection intensities of $\mathrm{NTi}$ and $\mathrm{Ni}_{4} \mathrm{Ti}_{3}$ phases are observed. It may confirm the fact that both phases exist in the implanted region. Moreover, along with the decreasing X-ray penetration depth in material, further increasing fractions of the $\mathrm{A}, \mathrm{Ni}_{4} \mathrm{Ti}_{3}$ and $\mathrm{NTi}$ phases were observed. For the thickness of this layer about $340 \mathrm{~nm}$, besides still existing austenite $(\mathrm{A}), \mathrm{Ni}_{4} \mathrm{Ti}_{3}$ and $\mathrm{NTi}$ phases, only one martensitic phase $\left(M_{\mathrm{v}}\right)$ is present in the alloy. Further decrease of the X-ray penetration depth to about $170 \mathrm{~nm}$ leads to intensity drop of diffraction lines for the martensitic phase. Simultaneously, the increasing fraction of the $\mathrm{Ni}_{4} \mathrm{Ti}_{3}$ and $\mathrm{NTi}$ phases takes place.

Crystallographic data for the identified phases in the ion-implanted NiTi alloy,

TABLE according to Powder Diffraction File-PDF-4 [10]

\begin{tabular}{|c|c|c|c|c|c|}
\hline Phase & $A$ & $M_{\mathrm{m}}$ & $M_{\mathrm{v}}$ & $\mathrm{Ni}_{4} \mathrm{Ti}_{3}$ & NTi \\
\hline type & $\mathrm{TiNi}$ & $\mathrm{NiTi}$ & $\mathrm{NiTi}$ & $\mathrm{Ni}_{4} \mathrm{Ti}_{3}$ & $\mathrm{TiN}$ \\
\hline PDF number & 04-002-7201 & $00-035-1281$ & 04-007-1534 & 00-039-1113 & 00-006-0642 \\
\hline system & cubic & monoclinic & monoclinic & rhombohedral & cubic \\
\hline space group & $P m-3 m(221)$ & $P 21 / m(11)$ & $P 21 / m(11)$ & $R-3(148)$ & $F m-3 m(225)$ \\
\hline \multirow{4}{*}{ cell } & \multirow{4}{*}{$a=0.3012 \mathrm{~nm}$} & $a=0.4622 \mathrm{~nm}$ & $a=0.2898 \mathrm{~nm}$ & \multirow{2}{*}{$a=1.1235 \mathrm{~nm}$} & \multirow{4}{*}{$a=0.424 \mathrm{~nm}$} \\
\hline & & $b=0.4120 \mathrm{~nm}$ & $b=0.4108 \mathrm{~nm}$ & & \\
\hline & & $c=0.2885 \mathrm{~nm}$ & $c=0.50789 \mathrm{~nm}$ & $c=0.4646 \mathrm{~nm}$ & \\
\hline & & $\beta=96.80^{\circ}$ & $\beta=97.78^{\circ}$ & $\gamma=120^{\circ}$ & \\
\hline
\end{tabular}

Based on the obtained results, the model of structure changes in the ion-implanted region of the NiTi alloy can be proposed. In the ion-implanted region, from the surface to a depth of $170 \mathrm{~nm}$ the sample exhibits three phases: the dominating austenite phase (A), the $\mathrm{Ni}_{4} \mathrm{Ti}_{3}$ and NTi phases and a small amount of $M_{\mathrm{v}}$ martensitic phase, and deeper - a mixture phase of martensitic and austenite. The crystallographic data for all identified phases are summarized in Table.

\section{Conclusions}

This work presents the X-ray study of structural and chemical composition evolution in the implanted NiTi alloy. The suggested structural changes in the surface modified material are based on the results obtained from the SIMS measurements as well as the observed X-ray diffraction effects. In the process of ion implantation of nitrogen with the fluence $10^{18} \mathrm{~cm}^{-2}$ and $50 \mathrm{keV}$ energy, the layered structure with different phase and chemical 
composition was formed. The modified surface layer is compositionally graded, there is no distinct interface between the surface modified layer and the bulk material. The obtained results demonstrated that ion implantation for such a fluence and energy is a promising technique for the surface modification of NiTi alloys.

\section{Acknowledgments}

The authors wish to express their thanks to Prof. A. Barcz of the Institute of Physics of Polish Academy of Sciences for his SIMS investigation.

\section{References}

[1] J. Humbeeck, Scr. Mater. 50, 179 (2004).

[2] D. Chrobak, H. Morawiec, Scr. Mater. 44, 725 (2001).
[3] H. Pelletier, D. Muller, P. Mille, J. Grob, J. Surf. Coat. Techn. 158, 309 (2002).

[4] S. Shapolovskaya, J. Andregg, J. Van Humbeck, Acta Biomater. 4, 447 (2008).

[5] L. Tan, W.C. Cron, Acta Mater. 50, 4449 (2002).

[6] S. Mandl, Surf. Coat. Technol. 201, 6833 (2007).

[7] Li Jinlong, M. Sun, X. Ma, G. Tang, Wear 261, 1247 (2006).

[8] A. Christemnson, E. Rowland, Trans. Am. Soc. Metals 45, 638 (1953).

[9] R.A. Yankov, N. Shevchenko, A. Rogozin, M.F. Maitz, E. Richter, W. Möller, A. Donchev, M. Schütze, Surf. Coat. Technol. 201, 6752 (2007).

[10] Joint Committee on Powder Diffraction Standards, JCPDS in: International Centre for Diffraction Data. Powder Diffraction File-PDF-4, ICDD, Pennsylvania 2008 (CDROM). 